\title{
Argumentos morais sobre inclusão/exclusão de idosos na atenção à saúde
}

Edna Estelita Costa Freitas ${ }^{1}$, Fermin Roland Schramm ${ }^{2}$

\section{Resumo}

O rápido envelhecimento populacional é a transformação demográfica mais significativa nos países em desenvolvimento. Grande parte dos pacientes internados nos centros hospitalares é de idosos, dispostos a se submeter a tratamento com a condição de retornar, após a alta, a um estado funcional de saúde semelhante ao prévio. Neste contexto, o atendimento às necessidades da população precisa de formação bioética adequada dos recursos humanos na área da saúde, voltada para a geriatria, inclusive no centro de tratamento intensivo (CTI). Mas na decisão da admissão do idoso nesses centros, os aspectos morais acabam sendo, sem justificativa cogente, subsumidos aos aspectos puramente técnicos, o que pode influenciar de maneira discriminatória a decisão, prejudicando, indevidamente, a população idosa. No presente trabalho serão abordados e criticados seis argumentos morais propostos contra a internação hospitalar do paciente geriátrico no CTI, à luz das ferramentas da bioética principialista e da bioética de proteção.

Palavras-chave: Bioética. Ética. Ética médica. Idoso. Terapia intensiva. Tomada de decisões.

\section{Resumen}

\section{Los argumentos morales sobre la inclusión/exclusión de personas mayores en el cuidado de la salud}

El rápido envejecimiento es el cambio demográfico más notable observado en los países en desarrollo. La mayoría de los pacientes que ingresan en centros hospitalarios es de ancianos que están dispuestos a someterse a un tratamiento para volver, después de su alta, a un estado funcional similar a la salud anterior. En este contexto, la atención a las necesidades de la población necesita una formación en bioética adecuada de los recursos humanos de salud que enfrentan la geriatría, incluso la Unidad de Cuidados Intensivos (UCI). Pero la decisión del anciano ingreso en la UCI, los aspectos morales llegan a ser, sin una justificación convincente, subsumido a los aspectos puramente técnicos, que pueden influir en la decisión de manera discriminatoria, dañando, indebidamente, la población anciana. En este trabajo se discuten y critican seis argumentos morales contra la admisión de ancianos en la $\mathrm{UCl}$ a la luz de las herramientas de la bioética principialista y de la bioética de protección.

Palabras-clave: Bioética. Ética. Ética médica. Ancianos. Cuidados intensivos. Toma de decisiones.

\begin{abstract}
Moral arguments about inclusion/exclusion of elderly people in health care

The fast population aging is the most significant demographic change observed in developing countries. Most patients admitted in hospital centers are the elderly, who are willing to submit themselves to treatments in order to return, after discharge, to a functional health status that is similar to the previous one. In this context, attention to the needs of population requires a proper bioethics training of human resources in health care toward geriatrics, including the Intensive Care Unit (ICU). However in the decision of elderly ICU admission, the moral aspects end up being subsumed to the purely technical aspects, with no cogent justification, what may influence the decision in a discriminatory manner, affecting the elderly population. In the present work, six moral arguments against the proposed hospital admission of geriatric patient into the ICU will be addressed and criticized in light of the tools of principlist bioethics and bioethics of protection.
\end{abstract}

Key words: Bioethics. Ethics. Ethics medical. Aged. Intensive care. Decision making.

1. Doutoranda eec1994@yahoo.com.br 2. Pós-doutor rolandschram@yahoo.com.br - Escola Nacional de Saúde Pública (Ensp)/ Fundação Oswaldo Cruz (Fiocruz), Rio de Janeiro/RJ, Brasil.

\section{Correspondência}

Fermin Roland Schramm - Rua Leopoldo Bulhões, 1.480, Sala 914 CEP 21041-210. Rio de Janeiro/RJ, Brasil. 
O rápido envelhecimento populacional é a transformação demográfica mais marcante observada nos países em desenvolvimento a partir da segunda metade do século XX. Especificamente no Brasil, destacam-se três aspectos no processo de envelhecimento populacional: 1) tal envelhecimento tem sido gradual e contínuo; 2) o segmento populacional dos idosos é aquele que mais cresce e; 3 ) em 2050, a população idosa provavelmente representará $22,71 \%$ da população total ${ }^{1}$.

Neste cenário, vem aumentando rapidamente o número de pacientes idosos e muito idosos ${ }^{2}$ necessitando de cuidados em ambiente hospitalar, fato que exige discernimento da parte do médico em relação à triagem de vagas que serão cedidas nos centros hospitalares aos pacientes, devido à escassez de leitos públicos disponíveis em unidades de saúde. Como, muitas vezes, os profissionais médicos estão pouco familiarizados com os conhecimentos bioéticos necessários para lidar com a conflituosidade implicada na prática da triagem para admissão hospitalar, os aspectos morais envolvidos na decisão acabam subsumidos aos técnicos, sem justificativa plausível. Isto acaba por influenciar a decisão de maneira discriminatória, prejudicando indevidamente a população idosa ${ }^{3}$.

Grande parte dos pacientes internados no hospital é de idosos que podem, em algum momento da internação hospitalar, estar na condição de necessitar admissão no centro de tratamento intensivo (CTI). Por exemplo, nos Estados Unidos da América (EUA) os idosos representam de $42 \%$ a $52 \%$ das internações ${ }^{4}$. Em relação à mortalidade, os idosos mais velhos (idade $>85$ ), com insuficiência de um único órgão, têm taxas de mortalidade que variam de $30 \%$ a $70 \%$. Naqueles com dois ou mais órgãos em falência, a mortalidade aumenta para $>80 \%{ }^{5}$. Apesar desses resultados, os pacientes idosos estão mais preocupados com a manutenção de suas funções cognitivas do que com os desfechos de mortalidade, e estão dispostos a se sujeitar a tratamento intensivo, mas com a condição de retornar a estado funcional comparável ao prévio ${ }^{6}$.

No entanto, alguns dados sugerem que a idade, enquanto tal, é fator prevalente na recusa à admissão no CTI como, por exemplo, no estudo europeu ${ }^{7}$ que mostrou que de 286 pacientes triados para possível internação no CTI, 48 não foram admitidos por serem considerados muito doentes para terem benefício no tratamento. Ademais, em 11 pacientes o critério foi apenas a idade (> 67 anos; odds ratio [OR],9.17; Confidence interval [CI], 95\%: 3,0-27,6) ${ }^{7-10}$. A utilização de tais critérios para exclusão na admissão pode ser considerada moralmente questionável,porque é discriminatória.

Outro estudo observacional prospectivo de decisões de triagem, que recebeu o acrônimo Eldicus ${ }^{11}$ (Triage Decision Making for the Elderly in European ICUs) e foi realizado em 11 CTI de sete países europeus, entre setembro de 2003 e março de 2005, avaliou cerca de 8.700 triagens em mais de 7.700 pacientes. Segundo Van Steendam ${ }^{12}$, pesquisador do estudo feito mediante análise do mapa social das práticas envolvidas nos $\mathrm{CTI}$, três critérios parecem prevalecer na escolha do paciente a ser admitido: a) a condição clínica no momento da admissão, em que se aceita ou se recusa o paciente; b) um conjunto de critérios objetivos de seleção (como a qualidade do benefício de ser admitido no (TI) e; c) uma velada discriminação dos idosos na admissão ${ }^{13}$.

Diariamente, o intensivista toma decisões sobre a seleção do doente a ser internado. O profissional enfrenta conflitos responsavelmente, pois sabe que sua decisão se baseia em fatores tanto técnicos (por exemplo, a gravidade da doença) como morais (como no caso de ter que escolher entre dois pacientes com idade diferente e a mesma gravidade de doença) ${ }^{14}$. Mas, na triagem hospitalar de pacientes idosos, surge frequentemente uma dúvida relevante do ponto de vista moral: a recusa em admitir os idosos para internação, pela simples razão do critério idade, não seria discriminatória e, portanto, injusta?

A este respeito, Rivlin ${ }^{15}$ enumera seis argumentos intuitivos, aparentemente de tipo pragmático (descritos abaixo), que considera inconsistentes para justificar a negativa na assistência à saúde do idoso pelas instituições sanitárias, mas que poderiam de fato ser utilizados para a recusa da internação do paciente geriátrico no $\mathrm{CTI}$, pelo médico intensivista, em referência à triagem por políticas etárias ${ }^{7}$ ou mesmo como forma de discriminação contra idosos ou ageism ${ }^{15}$ : 1 . Os idosos deveriam desistir das suas vidas em favor dos mais jovens; 2 . A idade é um critério para recusar/iniciar o tratamento; 3 . Os idosos ganham pouco com o tratamento; 4 . A sociedade tem poucos ganhos ao tratar de idosos; 5 . 0 tratamento deve alcançar o seu máximo benefício; 6 . A idade é um critério objetivo.

\section{Objetivo}

No presente trabalho os argumentos morais que podem ser utilizados pelo médico intensivista no processo de tomada de decisão para a recusa da admissão do idoso no $\mathrm{CTI}$, enumerados acima, serão analisados 
e criticados do duplo ponto de vista das ferramentas da bioética, principalmente da bioética principialista ${ }^{16}$, complementada pela bioética de proteção ${ }^{17}$. Estas duas propostas analíticas são aqui consideradas pertinentes e legítimas para a discussão da temática, pelas razões apresentadas a seguir. Objetiva-se demonstrar como ferramentas bioéticas podem ajudar a dirimir conflitos morais na prática médica, como aqueles gerados por eventual decisão discriminatória na negação de internação e, em particular, para dar conta da conflituosidade na alocação de vagas escassas de terapia intensiva para o paciente geriátrico.

\section{Método}

Este é um trabalho de reflexão sobre a moralidade da prática médica de inclusão ou exclusão de pacientes idosos na atenção à sua saúde, baseado em revisão bibliográfica realizada a partir de pesquisa na Biblioteca Virtual em Saúde (BVS). O levantamento, que abrange o período de 1992-2012, utilizou os seguintes descritores: 1) Português: "Medicina intensiva", "Tomadas de decisão", "Ética médica", "Ética biomédica", "Bioética", "Idoso"; 2) Espanhol: "Cuidados intensivos", "Toma de decisiones", "Ética médica", "Ética biomédica", "Bioética", "Ancianos"; 3) Inglês: "Intensive care", "Decision making", "Medical ethics", "Biomedical ethics", "Bioethics", "Aging". Foram selecionados 40 artigos em português, espanhol e inglês, e excluídos aqueles em outras línguas.

O referencial teórico para a discussão bioética dos dados coletados foi o principialismo descrito por Beauchamp e Childress ${ }^{16}$, utilizado para a reflexão sobre a inconsistência dos seis argumentos expostos por Rivlin ${ }^{15}$ (anteriormente listados) na recusa discriminatória da admissão do idoso para tratamento hospitalar e aplicados no CTI. Cada argumento será analisado segundo as razões que o tornam moralmente questionável para justificar a negação da internação do idoso, baseando-se na alocação de vagas apenas pelo critério da idade. Em seguida, será apresentada a bioética de proteção ${ }^{17}$ como forma complementar para auxiliar a bioética principialista a dar conta da conflituosidade na alocação de vagas escassas de terapia intensiva para o idoso, visto que se trata de população não meramente vulnerável, mas, sim, propriamente vulnerada.

\section{A bioética principialista}

À medida que as ciências biológicas e da saúde evoluem, conforme a vigência do paradigma biotec- nocientifico ${ }^{18}$, surgem novas possibilidades de intervenção sobre a vida das pessoas. As internações hospitalares, incluindo as do CTI, têm se revelado capazes de mudar o rumo de várias doenças, com maior ou menor desconforto dos pacientes. Consequentemente, tornou-se necessário elaborar critérios para decidir quais pacientes serão internados no CTI, definindo parâmetros para a tomada de decisão e considerando a variedade de sistemas de valores vigentes, não necessariamente compatíveis entre si, que poderão resultar em controvérsias morais sobre as atitudes corretas ou incorretas que são tomadas ou a serem tomadas - nas situações concretas vivenciadas pelos pacientes.

Tais critérios e sua necessária análise crítica, aplicada aos conflitos e aos argumentos em jogo nas propostas de soluções que possam ajudar nas decisões problemáticas do profissional que deve decidir corretamente o que fazer, integram parte da caixa de ferramentas da bioética. Assim, a tarefa do campo será tanto de tipo analítico quanto propriamente prático; analisando criticamente os conceitos e argumentos envolvidos, tentando avaliar sua consistência e cogência para uma decisão que possa ser considerada moralmente correta em uma situação determinada.

Em outros termos, a bioética, entendida como "ética prática" ${ }^{19}$, procura entender e tentar resolver os conflitos morais implicados pelas práticas nos âmbitos do viver e da saúde, tendo em conta o contexto da pluralidade de sistemas de valores, em princípio legítimos, em sociedades seculares e democráticas. Em particular, pode-se dizer que a bioética tem a tríplice função: 1) descritiva, pois analisa os conflitos em pauta do ponto de vista de um espectador em princípio racional e imparcial; 2) normativa com relação a tais conflitos, e isso em duplo sentido: (a) proscrevendo os comportamentos que podem ser considerados reprováveis e; (b) prescrevendo aqueles considerados corretos e em determinadas situações de desamparo; 3) protetora com relação aos pacientes morais caracterizáveis como "suscetíveis" ou até "vulnerados" - devido as suas incapacidades que não lhes permitem enfrentar o desamparo com seus próprios meios ou por outro dispositivo protetor ${ }^{20,21}$.

Para tanto, dentre as várias tendências existentes em bioética, pode-se destacar, em primeiro lugar, a bioética principialista de Beauchamp e Childress ${ }^{15}$. Com efeito, o principialismo surgiu com o movimento social em prol dos direitos civis, que levou, inclusive, à reivindicação do controle social sobre a prática médica e científica, de acordo com alguma escala de valores legítimos. A vertente principialista de 
Beauchamp e Childress propunha, especificamente, um modelo baseado nos quatro princípios prima facie de não maleficência, beneficência, autonomia e justiça.

O modelo principialista é considerado aplicável aos conflitos que podem surgir nas inter-relações médico-paciente da prática biomédica, haja vista que define parâmetros para a ação: a não maleficência requer que se evitem danos injustificados a terceiros; a beneficência valoriza os atos que proporcionem algum bem a terceiros; a autonomia atribui valor a escolha livre e intencional de agentes cognitiva e moralmente competentes; e a justiça determina que se proporcionem equitativamente benefícios, riscos e custos entre os envolvidos.

Aplicando tal modelo à avaliação da moralidade da tomada de decisão em admitir idosos no hospital e no CTI, dentre os quatro princípios bioéticos o da autonomia pode ser considerado o mais relevante, quando ocorre a recusa, ou não, do paciente em ser admitido e iniciar o tratamento, implicando, portanto, no respeito à livre vontade do titular daquela vida que está em jogo.

\section{Análise bioética dos argumentos}

\section{Os idosos deveriam desistir de suas vidas em favor dos mais jovens}

Embora seja intuitivamente compreensível que o médico utilize o argumento acima mencionado, em realidade não existe nenhuma razão cogente que nos force a pensar que em si uma diferença de idade entre duas pessoas - o idoso e o jovem - justifique a desigualdade na justa consideração dos respectivos interesses ${ }^{19,22}$. Com efeito, a característica "idade", considerada sozinha, não pode constituir fator de discriminação pois infringiria o princípio de igualdade e, portanto, a justiça, caracterizando caso de ageism.

Em particular, a igualdade é pressuposto ético básico que deve ser respeitado prima facie por todos os cidadãos de uma sociedade que se pretenda democrática, a qual também terá que lidar com a alocação justa dos recursos existentes, inclusive nos campos da saúde e no CTI. Assim, pode-se considerar injusta a crença de que os idosos devem desistir de suas vidas em favor dos jovens.

Entretanto, se considerarmos que o grupo populacional idoso é, em geral, um dos mais fragilizados de nossa sociedade, ele pode ser considerado, por isso, alvo legítimo de políticas públicas específicas que tenham em devida conta esta "suscetibilida- de", sendo merecedor de amparo, garantindo proteção aos seus direitos básicos de acesso à saúde por parte dos profissionais ${ }^{21,23}$.

\section{Idade como critério para recusar início de trata- mento}

De fato, em alguns CTI faz tempo que a idade é utilizada como critério ${ }^{24}$, sendo considerada constitutiva da atitude conhecida como ageism quando não for considerado, com a devida atenção, o fato de que seu uso continuado não se torne algo "natural" e, portanto, em princípio, moralmente inquestionável. Na realidade, tal atitude é moralmente questionável por ser discriminatória, devendo ser justificada com argumentos cogentes, que possam ser analisados e avaliados pela bioética.

Assim, durante a triagem de internação para o tratamento do idoso pode ser verificada a importância maior atribuída aos tradicionais princípios da ética médica de não maleficência e de beneficência, que se referem essencialmente aos deveres profissionais do médico pelo menos desde o código hipocrático - mas que nem sempre consideram a mudança de condições nas quais se dá atualmente a prática médica, devido à crescente incorporação de novas técnicas/procedimentos e à incorporação da cultura dos direitos humanos no saber-fazer dos profissionais de saúde. Em particular, segundo Beauchamp e Childress, o princípio da beneficência se refere à obrigação do agente moral em agir em benefício do paciente moral - mas, em tese, de acordo com uma escala de valores legítimos e aceita pelos envolvidos - e aqui se aplica ao comportamento esperado da equipe de intensivistas, que deve respeitar a livre vontade do paciente idoso (ou exercício da "autonomia").

Todavia, na prática, nos deparamos com uma importante limitação na aplicação deste princípio, pois o paciente em questão pode encontrar-se incapaz de opinar sobre o que considera benéfico ou não (devido à sedação, coma etc.). O que pode ser considerado benéfico para os médicos na verdade não reflete necessariamente a possível opinião do paciente no exercício de sua autonomia. De fato, a equipe poderia estar impondo ao paciente um tratamento não desejado, podendo, portanto, ser considerado contrário a seu possível "benefício" e, assim, julgado por ele como tal. Com efeito, no CTI trabalham médicos treinados para utilizar seu conhecimento essencialmente técnico e, acima de tudo, para não deixar de tratar os pacientes após terem sido admitidos, em particular de acordo com o objetivo - muitas vezes considerado como inquestionável - de "salvar vidas". 
Em consequência, por melhores sejam as intenções médicas no CTI, por mais que se queira ser "beneficente", é exatamente a definição de "bem" subjacente a tal princípio o principal obstáculo a essa atitude, pois não se tem consenso universal $a$ priori sobre o que é, ou deveria ser, o bem ${ }^{25}$. Assim sendo, a internação no CTI pode deixar de ser benéfica à medida que impõe ao paciente um sofrimento evitável, indo de encontro também ao princípio da não maleficência. Este pode ser o caso da admissão prolongada em unidade fechada, quando o paciente é submetido à rotina de procedimentos como punções para a coleta de sangue para exames laboratoriais; aspiração frequente de vias aéreas; uso de sonda nasoenteral etc., que são procedimentos invasivos capazes de provocar sofrimento, de fato evitável, e que podem se tornar um malefício se ministrados contra a vontade do idoso (ou se não forem para evitar a sua morte não desejada).

Em suma, neste caso devem ser devidamente ponderadas a vontade do paciente, suas concepções de bem e mal, e respeitada sua autonomia ${ }^{26}$; ou seja, deve-se procurar o equilíbrio, ou convergência, entre o poder do médico intensivista e as preferências do paciente, sobretudo quando estas forem explicitamente formuladas. Nesse sentido, salienta-se a importância de os profissionais médicos das mais diversas áreas informarem seus pacientes acerca das diretrizes antecipadas de vontade, para que, no uso de sua autonomia, possam cada vez mais expressar seus desejos diante das distintas situações clínicas.

Por fim, tem-se o princípio da justiça, aplicável à polêmica sobre o uso de vagas de escassos leitos de CTI, em relação ao qual se pode ter, por um lado, um conflito resultante do recurso, considerado escasso e aplicado a idosos sem condições de recuperação total (ou pelo menos "razoável"), e, por outro, uma situação que é de certa maneira o inverso da anterior, pois o paciente pode ter manifestado claramente o seu desejo de não se submeter a tratamentos considerados fúteis, certamente questionáveis do ponto de vista da justiça sanitária se considerarmos o próprio argumento da escassez de recursos.

No primeiro caso tem-se a difícil questão da efetividade de um procedimento que implica na justa ponderação entre custos e benefícios, isto é, que não prejudique os legítimos interesses dos pacientes. No segundo, algo relativamente menos problemático, pois é o próprio paciente que toma a iniciativa de não "desperdiçar" recursos escassos, o que pode ser visto como uma forma - embora talvez indireta - de favorecer a distribuição mais justa dos mesmos ${ }^{27}$.

\section{Os idosos ganham pouco com o tratamento}

Este argumento é também questionável, pois, em muitos casos, a resposta dos idosos ao tratamento é tão boa como a dos jovens. Nesse sentido, Jecker e Schneiderman ${ }^{28}$ afirmam que não existe diferença de idade significativa na mortalidade e morbidade associadas aos resultados de várias intervenções, incluindo sobrevida após ressuscitação cardiopulmonar, arteriografia coronária e revascularização cirúrgica, transplante de fígado e rim e outras cirurgias, quimioterapia e hemodiálise, dentre vários procedimentos.

Na realidade, os pacientes idosos internados no CTI, tanto quanto os jovens, podem apresentar intercorrências clínicas - por exemplo: infecções e delirium - ou ter que se submeter a procedimentos agressivos ou invasivos como a ventilação mecânica e, por vezes, posterior traqueostomia, se a necessidade de prótese respiratória se prolongar.

De fato, tais procedimentos têm potencial maior de deixar sequelas permanentes no idoso ${ }^{9}$ do que no jovem, como a piora da capacidade cognitiva pelo delirium, e a piora da capacidade pulmonar por ventilação mecânica prolongada. Ainda assim, durante a internação crítica pode-se ter a chance de não deteriorar a condição clínica de um paciente idoso, funcional e cognitivamente. Pode-se, ademais, obter ganhos futuros com a recuperação clínica total pela admissão e tratamento no CTI. Nesses casos tornar-se-ia necessário apenas o acompanhamento geriátrico em regime ambulatorial após a alta, retornando o idoso ao estado de saúde prévio à terapia intensiva. Com isso, poderá obter ganhos pessoais e permanecer produtivo sem sequelas ${ }^{29}$.

\section{A sociedade tem poucos ganhos ao tratar de idosos}

Este argumento se baseia no pressuposto de que o paciente idoso, submetido a diversos tratamentos dispendiosos, como diálise, uso de antimicrobianos de largo espectro, nutrição enteral e parenteral etc., sem perspectivas de recuperação e de retomar suas atividades, passa a ser o grande consumidor de escassos recursos que poderiam ser utilizados, de maneira mais efetiva, em pacientes com maior possibilidade de cura. Além disso, o uso "exagerado" da tecnologia do CTI em um único paciente pode representar um futuro sem opções terapêuticas para as internações que estão por vir, caso a velocidade de reposição de material e a disponibilidade de lugar sejam inferiores à velocidade de admissão. 
Nesse tipo de situação, realmente, questionase até que ponto a autonomia individual deva ser respeitada em detrimento do bem coletivo ${ }^{16}$. Porém, só porque as pessoas são idosas não significa que não possam contribuir com suas experiências de vida para o bem comum, como é o caso, por exemplo, das inter-relações entre avós e netos que, na prática, podem ser valiosas para a própria estrutura familiar. Ao contrário, acredita-se, preconceituosamente, que os idosos, em sua maioria, não participam diretamente do processo produtivo e, consequentemente, não teriam, em princípio, renda, tendo inclusive seu poder de decisão comprometido por perda da autodeterminação para lidar com as atividades cotidianas ${ }^{30}$.

Essa discussão é bastante difícil e, até o momento, não foi conduzida nos CTI, mas mostra a angústia presente no dia a dia dos profissionais intensivistas. De fato, as ações de distribuição de recursos apresentam limites e falhas, pois os recursos em saúde são reconhecidamente escassos, mas também porque nem sempre as ponderações morais necessárias acompanham as decisões técnicas e os hábitos de quem de fato decide. Mas, também poder-se-ia argumentar - de acordo com os ditames da saúde pública - que o problema não existiria se o dinheiro público fosse empregado em medidas de prevenção de saúde objetivando o envelhecimento saudável ${ }^{31}$.

Entretanto, e apesar desta argumentação poder ser prima facie pertinente e justificada - visto que o desperdício de recursos é fato constatável e ato não necessariamente inevitável, tornando-se problemático moralmente -, ela não responde satisfatoriamente às demandas crescentes de cuidados em saúde, que também dependem do envelhecimento populacional e da consequente necessidade de amparo da população idosa, que deverá ser garantido por tratar-se de um direito garantido, no Brasil, constitucionalmente. Cabe considerar, além disso, que mesmo com o melhor programa de promoção e prevenção à saúde o aumento da idade tende a aproximar a pessoa da morte, situação que, muitas vezes, implica em internação em CTI. Considerando-se a já analisada transição etária da população, isto implica dizer que a questão - inevitavelmente - surgirá, senão agora em breve futuro.

Frente a este emaranhado complexo, a percepção geral da sociedade brasileira é de que o atendimento hospitalar é defasado, de custo elevado e com desperdício evitável de recursos, e que os idosos sofrem com o abandono em hospitais ou asilos, que podem, portanto, ser vistos como luga- res ou dispositivos inadequados por serem fontes de sofrimento adicional a esta população, que pode ser - repetindo - evitado. Ao preconceito e ao desrespeito com os idosos, adiciona-se a "pobreza" de investimentos públicos para atendimento às necessidades da população idosa, como no caso da falta de instalações adequadas e a carência - tanto quantitativa quanto qualitativa - de recursos humanos em saúde ${ }^{32}$.

Esta realidade tem uma importante dimensão moral a ser destacada e analisada, apontando para a necessidade de mudanças e inovação nos paradigmas de atenção à saúde da população idosa, que sejam justas e resultem em propostas de ações diferenciadas, para que o sistema ganhe efetividade "com justiça" e o idoso possa usufruir integralmente dos anos proporcionados pelo avanço da biotecnociência ${ }^{18}$.

De fato, sabe-se que esse "viver mais" é importante à proporção que agregue qualidade aos anos adicionais de vida: a dimensão quantitativa (mais anos de vida) é inseparável daquela qualitativa (não mera sobrevida, mas vida com qualidade). Neste sentido, proteção, capacitação, autonomia e possibilidade de atuar em variados contextos sociais, além da elaboração de novos significados para a vida na idade avançada, se tornam ações necessárias para uma política destinada aos idosos que seja moral e politicamente correta em uma sociedade que se pretenda democrática e minimamente justa.

\section{O tratamento deve alcançar o seu máximo bene- fício}

Essa é uma afirmação problemática, apesar de sua aparente cogência em nome da efetividade, pois se os médicos decidissem tratar apenas com base no suposto máximo benefício do paciente, algumas decisões moralmente questionáveis seriam feitas, visto que muitas das pessoas com doença crônica ou doença com um prognóstico reservado não seriam tratadas, delineando-se a possibilidade de tratar-se de alguma forma de omissão questionável. Em particular, investir em um tratamento para o paciente idoso sem possibilidade de que ele retorne com as mesmas aptidões (ou pelo menos "parecidas") da sua vida anterior, por meio das opções terapêuticas do CTI - como diálise, ventilação mecânica -, pode ser considerado benéfico, pois vai ao encontro de outro princípio, o polêmico princípio da sacralidade da vida - que assegura o valor moral da existência humana em qualquer circunstância e que está expresso em nosso ordenamento jurídico público ${ }^{33}$. 
Assim sendo, é necessário destacar que se deve estabelecer o limite entre o que é o ato beneficente propriamente dito e o ato paternalista do médico em relação ao idoso nas tomadas de decisão sem consultar as preferências individuais e razoáveis dos pacientes, assumindo o que o médico supõe ser o melhor para eles. Neste caso, pode ocorrer despercebidamente a passagem de um saber-fazer em princípio "beneficente" para uma forma de exercício de poder, ou de biopoder, que poderá ser questionável pelas suas implicações autoritárias desnecessárias e moralmente questionáveis ${ }^{34}$.

Tal situação não é incomum na rotina do CTI, e é muito difícil de ser gerenciada porque quando a tomada de decisão é reservada, sem mais, ao médico (como no caso das emergências), este, em geral, não está preparado para delimitar a passagem subreptícia da atitude da beneficência para o paternalismo ${ }^{35}$. Em suma, de acordo com o modelo tradicional da relação entre médico e paciente, o médico representaria a legítima autoridade detentora dos conhecimentos técnicos e científicos que the outorgariam o direito de decidir a favor da postura supostamente mais correta em nome do que ele considera como melhor para o doente e tendendo, assim, a inibir a participação do paciente nos momentos de tomada de decisão sobre as ações a serem adotadas e que the dizem respeito. Por isso, os relacionamentos médico-paciente são muitas vezes explicitamente paternalistas, pois o médico decide a melhor forma de tratamento por uma transferência de autoridade do próprio paciente idoso ao intensivista, tendendo, portanto, a infantilizá-lo.

\section{A idade é um critério objetivo}

Este argumento é de cunho cientificista, pois se baseia no pressuposto de que a idade é um dado objetivo por ser numérico ou quantitativo e corroborado, por exemplo, pela própria epidemiologia, que forneceria as condições necessárias e suficientes para poder atuar corretamente, inclusive do ponto de vista moral. Entretanto, o argumento é também objeto de controvérsias porque implica, de fato, juízos de valor que podem promover, por exemplo, a discriminação dos idosos - como visto na análise do segundo argumento. Suponha-se, por exemplo, que seja usado o ponto de corte de 65 anos para tratamento. Isso significaria que uma cirurgia cardíaca que pudesse dar a uma paciente de 25-30 anos uma boa qualidade de vida, em um paciente que estivesse um dia após seu sexagésimo quinto aniversário, seria recusada sem exceções? Se a resposta for "sim", a atitude poderia ser vista como explicitamente discriminatória; mas se for "não", os defensores da adoção de uma política etária deveriam abrir uma exceção. Entretanto, negando o ponto de corte de 65 anos, estariam negando a própria política etária, perdendo assim o parâmetro da objetividade, supostamente fornecido epidemiologicamente.

De fato, a maioria da população considera que maisanosdevidasãoúteissomentesenãoforemacompanhados por dor, incapacidades ou demências ${ }^{36}$. Portanto, não se pode considerar que o estado de saúde da população seja medido apenas pela mortalidade e morbidade, mesmo que devidamente estudados pela epidemiologia. Neste sentido, devem ser providenciadas medidas mais objetivas do estado de saúde dos idosos - além da idade - que considerem atentamente a inovação no conceito de saúde, o que demandará estudos científicos sobre esta nova percepção, que tenham em conta as maneiras de como o tratamento poderia ser avaliado, também, do ponto de vista moral do paciente competente, e não somente com base no resultado técnico e científico.

\section{A bioética de proteção}

Considerando todas essas possíveis críticas à recusa do paciente idoso no CTI, o modelo principialista, embora relevante para analisar os conflitos que ocorrem na prática clínica, não é, ainda, suficiente para o debate sobre a tomada de decisão do tratamento apropriado de idosos no CTI, pois, apesar de bastante focado na inter-relação médico-paciente e na autonomia do paciente, não dá conta de situações relacionadas à coletividade e ao impacto do envelhecimento populacional nos recursos para a saúde brasileira ${ }^{37}$. Sob esta ótica, propomos utilizar a bioética de proteção, que pode ser vista como uma ferramenta para as discussões bioéticas no campo da saúde pública ${ }^{16}$, inclusive em relação a tomadas de decisão moral do médico em referência a admissão, ou não, do paciente idoso no CTI, quando tal paciente se encontra na condição de sujeito vulnerado ${ }^{38}$. Neste caso, proteger se torna prioritário frente a outras atitudes como as analisadas pelo principialismo.

Com efeito, a bioética de proteção visa a condição humana em suas formas concretas de efetiva vulneração, podendo ser aplicada tanto às situações conflituosas das relações interpessoais entre médico e paciente como aos conflitos em saúde pública, como podem ser aqueles que surgem entre formuladores de políticas públicas de saúde, os gestores 
de tais políticas e os usuários do sistema, que devem ser considerados, aqui, os destinatários legítimos da proteção, como pode ser o caso dos idosos discriminados pela idade. Com efeito, é razoável exigir de um Estado, que se pretenda moralmente legítimo e pragmaticamente eficiente, medidas protetoras em princípio capazes de dar conta da fragilidade da vida - não só ante antigas ameaças (como doenças e incapacidades), mas também antecipando possíveis e prováveis soluções à vulneração das pessoas, como a circunstância, aqui em exame, dos pacientes de CTI e das decisões que lhes dizem respeito ${ }^{16}$.

Neste sentido, a vulneração dos idosos incapazes de tomar autonomamente uma decisão correta que garanta a melhor qualidade de vida no tempo que lhes resta, poderia, em princípio, ser amenizada com o compromisso da equipe em fornecer todas as informações necessárias ao esclarecimento da família, lançando mão da ajuda de outros profissionais, como psicólogos e até mesmo bioeticistas. Mas, aqui, não podemos esquecer que as próprias famílias queixam-se de médicos pouco acessíveis e autoritários em suas decisões ${ }^{39}$. Parece, então, chegado o momento de o Estado intervir, elaborando políticas sanitárias capazes de propiciar soluções razoáveis e justas desse tipo de conflito, como a triagem do idoso no CTI. Em outras palavras, diante de pacientes considerados "idosos fora de possibilidade terapêutica" - mas que deveriam ser chamados, mais apropriadamente, "fora de possibilidade de cura" ${ }^{40}$ haja vista a possibilidade atual de prolongar a terapia - ou daqueles que não querem suas vidas perpetuadas dentro do CTI, parece que chegou o momento de termos políticas sanitárias que estimulem os cuidados paliativos e que visem ao conforto e a preservação da dignidade humana como componentes essenciais da qualidade de vida dos pacientes vulnerados.

\section{Considerações finais}

O presente trabalho, depois de apresentar possíveis argumentos morais para a adoção da controversa alocação de vagas baseada exclusivamente na idade por parte dos intensivistas, lançou mão de algumas ferramentas da bioética na tentativa de melhor refletir sobre as implicações morais da tomada de decisão para o processo de admissão do idoso no CTI, como, por exemplo, a reflexão sobre o conflito que pode ocorrer entre o argumento de que todas as decisões tomadas pela equipe médica devem sempre buscar preservar os melhores interesses do paciente idoso, os quais seriam su- postamente conhecidos pelo médico e a equipe, e o argumento de que tais interesses podem incluir preferências dos pacientes diferentes daqueles da equipe, e que podem, portanto, entrar em conflito entre si. $\mathrm{Na}$ realidade, o respeito à autonomia do paciente competente tem importante peso nas decisões, pois se ele for capaz de entender a situação e comunicar suas preferências, pode e deve participar das decisões sobre a admissão no CTI, desde que manifeste, direta ou indiretamente, tal interesse.

Portanto, o paciente idoso e a família devem ser informados e esclarecidos sobre os motivos da indicação ou não da internação no CTI para poderem participar, quando possível, ativamente da decisão; inclusive privilegiando as vontades do paciente idoso ou dos familiares (quando ele apresentar-se incapaz ou fizer esta opção) devidamente esclarecidos. Um caso grave de conflito moral é aquele que pode surgir frente a um paciente idoso, sem condições de recuperação, ser internado no $\mathrm{CTI}$, ocupando a vaga que poderia ser disponibilizada para outro paciente com melhores chances de recuperação, sendo cada vez mais distante a possibilidade de morrer em paz e com dignidade. De fato, o processo de tomada de decisão médica, relativa a pacientes idosos, remete à espinhosa questão da microalocação de recursos, considerados escassos quando não finitos. Neste âmbito, a discussão moral pelos profissionais de saúde intensivistas no CTI corre sempre o risco de ficar restrita ao campo técnico, o do saber-fazer médico ${ }^{41}$.

Concluindo: somente por meio da educação, como, por exemplo, a inclusão da bioética na graduação para toda a comunidade médica e, principalmente, para aqueles profissionaisligados-direta ou indiretamente - à área da medicina intensiva, mudar-se-ão as atitudes incorretas em relação aos idosos em estado de saúde crítico. De fato, o paciente na velhice é sempre um outro, que é também único, independentemente da idade cronológica, da gravidade da doença, do motivo da internação, do estado neuropsiquiátrico e da expectativa de vida. Em suma, a atenção deve ser centrada na pessoa e na dignidade humana; ou seja, conferindo importância a histórias, juízos, crenças e preferências dos idosos, e nos colocando a favor do seu bem-estar, tendo sempre como referencial maior a autonomia do idoso cognitiva e moralmente competente para exercê-la em suas decisões legítimas e que lhe dizem respeito, inclusive nos últimos momentos de sua vida. 


\section{Referências}

1. Instituto Brasileiro de Geografia e Estatística. Projeção da população por idade e sexo - 19802050: revisão 2008. [Internet]. Rio de Janeiro: IBGE; 2008 [acesso 10 fev. 2012]. (Estudos e Pesquisas. Informação demográfica e socioeconômica; 24). Disponível: http://www.ibge.gov.br/ home/estatistica/populacao/projecao_da_populacao/2008/projecao.pdf

2. Veras R, Lourenço R, Martins $C$, Sanchez $M$, Chaves P. Novos paradigmas do modelo assistencial no setor saúde: consequência da explosão populacional dos idosos no Brasil. In: Veras R, organizador. Terceira idade: gestäo contemporânea em saúde. Rio de Janeiro: Relume Dumará; 2002. p. 11-79.

3. Machado J. Tomada de decisão na atenção ao paciente muito idoso hospitalizado [tese]. Porto Alegre: Pontifícia Universidade Católica do Rio Grande do Sul; 2006.

4. Marik PE. Management of the critically ill geriatric patient. Crit Care Med. 2006;34(9 Suppl):S176-82.

5. Angus D, Kelley M, Schmitz R, White A, Popovich J. Caring for the critically ill patient. Current and projected work force requirements for care of the critically ill and patients with pulmonary disease: can we meet the requirements of an aging population? Jama. 2000;284(21):2.762-70.

6. Kass J, Castriotta R, Malakoff F. Intensive care unit outcome in the very elderly. Crit Care Med. 1992;20(12):1666-71.

7. Garrouste-Orgeas M, Montuclard L, Timsit JF, Misset B, Christias M, Carlet J. Triaging patients to the ICU: a pilot study of factors influencing admission decisions and patient outcomes. Intensive Care Med. 2003;29(5):774-81.

8. Hanson L, Danis M. Use of life-sustaining care for the elderly. J Am Geriatr Soc. 1991;39(8):772-7.

9. Boumendil A, Somme D, Garrouste-Orgeas M, Guidet B. Should elderly patients be admitted to the intensive care unit? Intensive Care Med. 2007;33(7):1252-62.

10. Pisani MA. Considerations in caring for the critically ill older patient. J Intensive Care Med. 2009;24(2):83-95.

11. Medical Economics and Research Centre, Sheffield. Eldicus: triage decision making for the elderly in european ICUs. [Internet]. Sheffield: MECS, [acesso 2 fev. 2012]. Disponível: http://www. mercs3510.fsnet.co.uk/Research/ELDICUS/eldicus.html

12. Van Steendam G. Eldicus studies: social map. [Internet]. Sprung C, compilador. Israel; c2006 [acesso 4 fev. 2012]. Disponível: http://www.ethics.org.il/eldicus/social_map.htm

13. Menezes RA. Difíceis decisões: uma abordagem antropológica da prática médica em CTI. Phisys. 2000;10(2):27-49.

14. Cosgriff J, Pisani M, Bradley E, O'Leary J, Fried T. The association between treatment preferences and trajectories of care at the end-of-life. J Gen Intern Med. 2007;22(11):1566-71.

15. Rivlin MM. Protecting elderly people: flaws in ageist arguments. Br Med J. 1995;310(6.988):117982.

16. Beauchamps TL, Childress JF. Princípios de ética biomédica. São Paulo: Loyola; 2002.

17. Schramm FR, Kottow M. Bioethical principles in public health: limitations and proposals. Cad Saúde Pública. 2001;17(4):949-56.

18. Schramm FR. Paradigma biotecnocientífico e paradigma bioético. In: Oda LM, editor. Biosafety of transgenico organisms in human health products. Rio de Janeiro: Fiocruz; 1999. p. 109-27.

19. Singer P. Ética prática. $2^{a}$ ed. São Paulo: Martins Fontes; 1998. p. 20.

20. Schramm FR. Bioética para quê? Revista Camiliana da Saúde. 2002;2(1):14-21.

21. Schramm FR. Bioética da proteção: ferramenta válida para enfrentar problemas morais na era da globalização. Rev bioét (Impr.) 2009;16(1):11-23.

22. Evans J. Quality of life assessments and elderly people. In: Hopkins A, editor. Measures of the quality of life. London: Royal College of Physicians; 1992. p. 109-33.

23. Schramm FR. Bioética sem universalidade? Justificação de uma bioética latino-americana e caribenha de proteção. In: Garrafa V, Kottow M, Saada A, organizadores. Bases conceituais da bioética: enfoque latino-americano. São Paulo: Gaia; 2006. p. 143-57.

24. Dudley N, Burns E. The influence of age on policies for admission and thrombolysis in coronary care units in the United Kingdom. Age Ageing. 1992;21(2):91-5.

25. Engelhardt HT Jr. Os fundamentos da bioética. São Paulo: Loyola; 1998.

26 Kant I. A crítica da razão prática. $2^{\mathrm{a}}$ ed. São Paulo: Martins Fontes; 2008.

27. Medeiros M. Princípios de justiça na alocação de recursos em saúde. [Internet]. Rio de Janeiro: Instituto de Pesquisa Econômica Aplicada; dez. 1999 [acesso jan. 2012]. (Ipea. Texto para discussão; $n^{\circ}$ 687). Disponível: http://www.ipea.gov.br/pub/td/1999/td_0687.pdf

28. Jecker NS, Schneiderman LJ. Futility and rationing. Am J Med. 1992;92(2):189-96.

29. Brandstetter RD. Intensive care for the elderly: should the gates remain open? N Y State J Med. 1992;92:175-6.

30. Lima-Costa MF, Barreto SM, Giatti L. Condições de saúde, capacidade funcional, uso de serviços de saúde e gastos com medicamentos da população idosa brasileira: um estudo descritivo baseado na Pesquisa Nacional por Amostra de Domicílios. Cad Saúde Pública. 2003;19(3):735-43.

31. Veras R. Envelhecimento populacional contemporâneo: demandas, desafios e inovações. Rev Saúde Pública. 2009;43(3):548-54. 
32. Veras R. Fórum envelhecimento populacional e as informações de saúde da Pnad: demandas e desafios contemporâneos. Cad Saúde Pública. 2007;23(10):2.463-6.

33. Mori M. A bioética: sua natureza e história [Internet]. [acesso 23 jan. 2012]. Disponível: http:// www.anis.org.br/Cd01/comum/TextoPosGraduacao/posgraduacao_texto_07_mori_port.pdf

34. Schramm FR. A autonomia difícil. [Internet]. Bioética. 1998 [acesso 23 jan. 2012];6(1):27-37. Disponível: http://pt.scribd.com/doc/5581396/Schramm-Autonomia-Dificil

35. Häyry H. Paternalism. In: Chadwick R, editor. Encyclopedia of applied ethics. San Diego: Academic Press; 1998. p. 449-57.

36. Paschoal SMP. Autonomia e independência. In: Papaléo-Netto M, editor. Gerontologia. São Paulo: Atheneu; 1996. p.313-23.

37. Camarano AA. Envelhecimento da população brasileira: uma contribuição demográfica. Brasília: Ipea; 2002.

38. Schramm FR. A moralidade da biotecnociência: a bioética da proteção pode dar conta do impacto real e potencial das biotecnologias sobre a vida e/ou a qualidade de vida das pessoas humanas? In: Schramm FR, Rego S, Braz M, Palácios M. Bioética, riscos e proteção. $2^{\mathrm{a}}$ ed. Rio de Janeiro: UFRJ/Fiocruz; 2009. p. 15-28.

39. Albuquerque I. Bioética, proteção e o fim da vida: o paciente como vítima e vetor de patógenos multirresistentes em UTIs [dissertação]. Rio de Janeiro: Ensp; 2007. p. 17.

40. World Health Organization. National Cancer Control Programmes: policies and managerial guidelines. $2^{\text {nd }}$ ed. Geneve: WHO; 2002.

41. Freitas EEC, Schramm FR. A moralidade da alocação de recursos no cuidado de idosos no centro de tratamento intensivo. Rev Bras Ter Intensiva. 2009;21(4):432-6.

\section{Participação dos autores}

Edna Estelita Costa Freitas e Fermin Roland Schramm escreveram o artigo e o segundo o revisou.

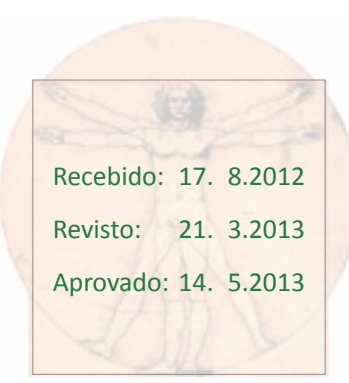

